\title{
Status Quo, Problems and Countermeasure Research of Home-Based Care Service Market in China-A Case Study of Sichuan Province
}

\author{
Jianping Lu \\ Business School, Sichuan Normal University, Chengdu, China \\ Email: lujp2002@163.com
}

Received 28 September 2015; accepted 13 November 2015; published 17 November 2015

Copyright (C) 2015 by author and Scientific Research Publishing Inc.

This work is licensed under the Creative Commons Attribution International License (CC BY). http://creativecommons.org/licenses/by/4.0/

(c) (i) Open Access

\begin{abstract}
This paper makes a case study of Sichuan Province where a large number of aging population lives. By the social investigation method, 350 aged community people are interviewed to discuss the conflict between supply and demand in the current home-based care service market and the problems arising out of the market-oriented operation. In addition, this paper brings about specific countermeasures and recommendations, with a view to give full play to the role of marketoriented mechanism in optimized allocation of resources, and to inspire participancy of various forces into home-based care service market, thus diversifying the home-based care service providers and provision modes in China, and greatly improving the QOL (quality of life) of the elderly.
\end{abstract}

\section{Keywords}

Home-Based Care Service, Demand, Supply, Problems, Countermeasures

\section{Introduction}

As the only country whose aging population exceeds 100 million in the world, China is witnessing more than $3 \%$ growth rate of aging population, representing 5 times of the population growth rate for the same period. It is estimated that the aging population will reach 438 million by 2050, showing a $28.76 \%$ of aging rate [1]. In light of the economic and social development situation in China, "age before it gets rich", "no official guarantee before aging" are deemed the two fundamental realities of the country. Meanwhile, China's population aging is accompanied with industrialization \& urbanization process and middle income trap; under this circumstance, the 
problem of aging is exceptionally serious across the world. Sichuan Province, ranking the fourth place in terms of population size, is challenged by the more serious aging situations, presenting several features including large aging population base (ranking the second place in China), rapid aging growth rate, advanced age, large number of empty-nest elderly, more intensive rural aging phenomenon, etc. According to the sixth National Population Census held in 2010, Sichuan Province has 80.4175 million of permanent resident population, accounting for about $6.03 \%$ of total population in China. The population exceeding 65 years and above is 8.8055 million, making up $10.95 \%$ of total population in Sichuan Province, $2.08 \%$ higher than the national average level. Additionally, according to the data obtained from the subject research report "Estimation on Population Aging in Sichuan Province for the Future 30 Years Based on the Sixth National Population Census Results" prepared by Sichuan Provincial Aging Population Department, Sichuan will encounter exceptionally serious aging situation in the forthcoming 30 years. It is estimated that the total population up to or exceeding 60 years will make up more than $25 \%$ of total populations in Sichuan Province by no later than 2027, and will exceed 33\% by no later than 2036. Population aging imposes profound impact upon economical and social aspects of Sichuan Province, and the growing demands for pension, medical treatment and social service are required by a large number of aging population. However, the elderly care service in Sichuan Province, especially the "9073" mainstream care service, is not improved. For this, the elderly care service shall be advanced by giving full play to the role of market-oriented mechanism provided that the guidance and instruction from competent governmental agencies shall be provided.

\section{Survey on Demands for Home-Based Care Service in Sichuan Province}

During October 2014 to February 2015, the Author, by questionnaire survey method, has made survey on the demands for home-based care service in major communities of Sichuan Province. In this survey, 380 questionnaires are distributed totally and 350 are collected, including 331 valid ones.

\subsection{Basic Information about the Respondents}

Among the 331 valid questionnaires, 133 questionnaires are completed by male respondents, accounting for $40.20 \%$ of the total, and 198 questionnaires completed by female respondents, making up $59.80 \%$. The average age of all respondents is 72.65 years. A majority of respondents have married and accompanied with spouses, totaling 198 persons, accounting for 59.82\% of the total respondents. 95 respondents are widowed, accounting for $28.7 \%$ of the total; 32 respondents are divorced, 9.67\%; and 6 respondents are unmarried, making up 1.81\%. Among them, 198 respondents live together with their spouses, accounting for 59.82\%, 85 respondents live together with their children, $25.73 \%$; 48 respondents live alone, $14.45 \%$. A majority of respondents before retirement are peasants, making up $19.94 \%$ of the total respondents; followed by the common technicians, accounting for $15.71 \%$. The respondents who are individual businesses share $15.11 \%$ and handicraftsman make up $10.27 \%$. The remainders who are engaged in other industries only make up less than $10 \%$ of the total.

\subsection{Economic and Health Status of the Respondents}

There are 85 respondents whose monthly income is lower than RMB 1000 accounting for $25.68 \%$ of the total respondents, 90 respondents whose monthly income is between RMB 1000 and RMB 2000, 27.19\%; 65 respondents who monthly income between RNB 2000 and RMB 3000, 19.64\%; 91 respondents whose monthly income exceeds RMB 3000, 27.49\%. There are 177 respondents who are capable of taking care of them, accounting for $53.47 \%$ of the total respondents; 119 respondents who are semi-self-cared, 35.93\%; 35 respondents who are fully incapable to care for themselves, $10.57 \%$.

\subsection{Demands of the Respondents for Home-Based Care Service}

Among the respondents, there are 279 respondents who are eager for household management service (sweeping, cloth cleaning, fee paying agent, repair and maintenance of household appliances), accounting for $84.29 \%$ of the total respondents; 145 respondents who desire safety care service (bath help, accompanied shopping, etc.), accounting for $43.81 \%$, 90 respondents who wish for day-care center service, making up 27.19\%, and 105 respondents who desire elderly meal delivery service, sharing $31.72 \%$. There are 113 respondents who wish for medicine dispensing and buying agent service, accounting for 34.14\%; 118 respondents who hope for accompanied 
medical treatment, accounting for 35.65\%; 250 respondents desiring periodic door-to-door physical inspection, sharing 75.53\%; 133 respondents requiring health-care consultation, making up 40.18\%; 110 respondents who wish for professional health care, 33.23\%; 139 respondents expecting health-care lecture, 41.99\%; 77 respondents who hope for getting recovery instructions, 23.26\%; 66 respondents desiring home bed service, 19.94\%; and 13 respondents expecting to get other care service, 3.93\%. There are 148 respondents who desire door-todoor reading and chatting service, accounting for $44.71 \%$; 82 respondents desiring professional psychological consultation service, 24.77\%; 218 respondents who wish for development of periodic recreational activities, 65.86\%; 203 respondents who expect to diversify the community activities, 61.33\%; 27 respondents desiring legal consolation service, $8.16 \%$; 18 respondents desiring matchmaking service, 5.44\%.

According to the survey and analysis above, it is revealed that the elderly in Sichuan Province has great and urgent demands for home-based care service, especially in the aspects of daily care, medical treatment, health and psychological aid. This is the precondition and basis for market-oriented operation of home-based care service.

\section{Analysis of Current Situation Concerning Supply of Home-Based Care Service in Sichuan Province}

As shown in Table 1, in recent years, Sichuan Province achieve rapid growth rate in economic and social development. The living standard and social security indicators (including the per capita disposable income and consumption expenditure of urban and rural residents, number of urban and rural residents maintaining endowment insurance, total beds provided by elderly service institutions, etc.) present a substantial growth trend. According to the Statistical Communiqué of Sichuan Province on the National Economic and Social Development, the per capita disposable income of urban and rural residents in Sichuan Province was RMB 15,461 in 2010, up to RMB 24,381 in 2014, representing a growth rate of $12 \%$; the per capita consumption expenditure of urban and rural residents across Sichuan Province grew from RMB 12,105 in 2010 to RMB 18,027 in 2014, witnessing an annual growth rate of $10.68 \%$; the per capita net income of rural residents increased from RMB 5140 in 2010 to RMB 8803 in 2014, with annual growth rate up to $14.82 \%$; the per capita consumption expenditure of rural residents was RMB 3896.7 in 2010 and increased to RMB 6906 in 2014, representing an annual growth rate of $14.66 \%$. The number of urban and rural residents maintaining endowment insurance witnesses a rapid growth, increasing from 13.11 million in 2010 to 30.139 million in 2014. In addition, the total beds provided by elderly service institutes experience substantial increase: additional 3155 beds are provided by the state-run urban elderly social welfare institutes across Sichuan Province in 2010; 152 rural central gerocomiums were newly built and expanded, providing 11,000 beds. 8313 kinds of urban community service facilities are made available and 781 community service centers were built. In 2011, the total beds of elderly care service institutes (excluding rural gerocomiums) reached 57,096; and 112 rural central gerocomiums were newly built and expanded, providing 12000 beds. 4819 urban community service centers (station) are established. In 2012, the total beds of elderly care service institutes in Sichuan Province reached 319,000, and 2937 urban community service centers (station) were established. In 2013, the total beds of elderly care service institutes in Sichuan Province attained to 336,000 , including 5525 beds provided by the 73 newly-built or expanded rural central gerocomiums, and

Table 1. Resident income, consumption, insurance procurement and care bed in Sichuan Province during 2010-2014.

\begin{tabular}{|c|c|c|c|c|c|c|c|c|c|c|}
\hline \multirow{3}{*}{ Year } & \multicolumn{4}{|c|}{ Urban residents } & \multicolumn{4}{|c|}{ Rural residents } & \multirow{3}{*}{$\begin{array}{c}\text { Population maintaining } \\
\text { endowment } \\
\text { insurance }(10,000)\end{array}$} & \multirow{3}{*}{$\begin{array}{l}\text { Total beds for } \\
\text { elderly care } \\
\text { service }(10,000)\end{array}$} \\
\hline & \multicolumn{2}{|c|}{$\begin{array}{l}\text { Per capita } \\
\text { net income }\end{array}$} & \multicolumn{2}{|c|}{$\begin{array}{c}\text { Per capita } \\
\text { consumption expenditure }\end{array}$} & \multicolumn{2}{|c|}{$\begin{array}{l}\text { Per capita } \\
\text { net income }\end{array}$} & \multicolumn{2}{|c|}{$\begin{array}{c}\text { Per capita } \\
\text { consumption expenditure }\end{array}$} & & \\
\hline & $\begin{array}{c}\text { Amount } \\
\text { (yuan) }\end{array}$ & $\begin{array}{l}\text { Growth } \\
\text { rate (\%) }\end{array}$ & $\begin{array}{c}\text { Amount } \\
\text { (yuan) }\end{array}$ & $\begin{array}{l}\text { Growth } \\
\text { rate (\%) }\end{array}$ & $\begin{array}{c}\text { Amount } \\
\text { (yuan) }\end{array}$ & $\begin{array}{l}\text { Growth } \\
\text { rate (\%) }\end{array}$ & $\begin{array}{c}\text { Amount } \\
\text { (yuan) }\end{array}$ & $\begin{array}{l}\text { Growth } \\
\text { rate (\%) }\end{array}$ & & \\
\hline 2010 & 15,461 & 11.7 & 12,105 & 11.5 & 5140 & 15.1 & 3896.7 & 11.6 & 1301.1 & \\
\hline 2011 & 17,899 & 15.8 & 13,696 & 13.1 & 6128.6 & 20.5 & 4675.5 & 20.0 & 1494.0 & \\
\hline 2012 & 20,307 & 13.5 & 15,050 & 9.9 & 7001.4 & 14.2 & 5366.7 & 14.8 & 1614 & 31.9 \\
\hline 2013 & 22,368 & 101 & 16,343 & 8.6 & 7895 & 12.8 & 6127 & 14.2 & 3001.6 & 33.6 \\
\hline 2014 & 24,381 & 9.0 & 18,027 & 10.3 & 8803 & 11.5 & 6906 & 12.7 & 3013.9 & 36.1 \\
\hline
\end{tabular}


2940 urban community service centers (station) were established. In 2014, the total beds of elderly care service institutes in Sichuan Province reached 361,000, and 10,276 community service institutes were established, including 6806 urban community service organizations.

It is revealed that Sichuan Province, for dealing with the population aging dilemma, did efforts to make up the shortfall in terms of insufficient supply of endowment service and made a significant progress. However, compared with the increasing population aging rate and the urgent demands of the elderly for house-based care service, the efforts are not enough. To solve the problems arising in the house-based care service market in Sichuan Province, specific countermeasures and recommendations shall be given.

\section{Problems in the Current House-Based Care Service Market}

\subsection{Dislocation of Governmental Function in House-Based Care Service}

At present, the governmental agencies assume much house-based care work which should not have been assumed, resulting in "offside" and "default" of government functions and unsatisfactory situation under which social resources fail to allocated appropriately through market-oriented mechanism [2].

Offside of government functions means that governmental agencies undertake many functions that should not have been implemented in the process of administrative actions. Offside of government functions in house-based care service includes both functional offside and relationship offside. Typical functional offside is manifested by direct organization and undertaking of cultural or recreational activities in communities, volunteer programs, scientific popularization, nonprofit nature of charity or contribution activities, etc. In the short term, active participation by government may impose a remarkable influence on the rapid development of house-based care service. But in the long term, development and growth of non-governmental organizations and volunteer organizations is the sound strategy for resolution. The government shall gradually hand over the foregoing house-based care work to non-governmental organizations, volunteer organizations and civil associations. Typical relationship offside is reflected by the administrative subordinating relationship between the governmental function departments and non-governmental associations. Such relationship should be the relationship of guidance and coordination, service and supervision. For example, the social work services in communities become the subsidiaries of governmental function departments, and caseworkers are considered as administrative staff serving governmental agencies. Under this circumstance, the social associations can not expressly define their responsibilities and duties; in turn, the growth and development of those associations will be affected adversely.

"Default" of government function means the government fails to play its own role in the home-based care services by failing to do or not doing well its own work, which specifically demonstrates in three fields, namely, investment, service management as well as social organization fostering and supporting. As for investment, some local governments fail to list the home-based care services on their financial budgets, therefore, their investments in the home-based care services are severely insufficient, and related financial investments are randomly used or run off without fund supervision and restraint of standards and specifications. As for service management, the government fails to develop sound plans and management laws and rules, and the present situation is, the government is governing something it should not govern and ignoring something it should govern. And as for social organization fostering and supporting, the government fails to formulate related government policies to support the sustainable and health development of social organizations, meanwhile, social organizations' development is greatly restrained due to insufficient fund support from the government.

\subsection{Unsound Operation of Market-Oriented Mechanism}

Excessive intervene of government narrows enterprises’ profit-making space. In the house-based care service fields, the government shall, as the manager or supervisor, be responsible for industry planning, providing initial funds and controlling service quality, other than direct provision of house-based care service to the elderly. But in practice, some local governments, influenced by traditional mind setting, intend to take care of every single thing personally; as a consequence, the participation by civil associations into house-based care service market is impaired and the profit-making space of relevant enterprises are narrowed, thus the growth and development of relevant civil associations and enterprises are suppressed [3].

Relevant enterprises have no good understanding of the market-oriented mechanism, and the relationship between market demands and supply is unbalanced seriously. With increasing aging speed, the elderly has 
growing demands for house-based care service. However, many civil associations and enterprises have no good knowledge of the emerging industry, and most of enterprises seem that the house-based care service industry represents small profits even loss and are loath to participate into such market. Therefore, the house-based care service market is at initial exploration phase, and the house-based care service products are single. There is a gap to be filled between the actual demands of the aged and actual supply. Different care service requirements fail to be satisfied for the elderly at different living levels.

Actual and valid demands of the elderly are insufficient, and scale economies effect can not be achieved. At present, the mode of providing for the aged in China is in transition from house-based care service to social providing for the aged. The traditional idea of elderly support is quite difficult to be changed and a large number of old people fail to accept the mode of house-based care service. Therefore, real and valid market demands have not been generated, thus scale economies effect is impossible. Some house-based care service programs forming the initial market shape failed to achieve sufficient coverage due to shortage of scientific planning and scatter industry layout. The number of service objects of such programs range from several hundreds to a dozen. As a consequence of small industrial scale, the enterprises are bound to increase service price to offset costs and achieve profits. However, the economic income of the elderly is at low level and they can not afford high-price service; in this case, the demands of the elderly are not real and valid one, as a result, the market must shrink and the development of house-based care service industry will be impaired.

\subsection{Deficient House-Based Care Service Professionals}

According to the Survey on Status Quo of Elderly Support Professional Team prepared by the Department of Social Welfare and Charity Promotion in June 2013 through developing questionnaire survey and interview in 15 provinces (municipalities, autonomous regions) including Beijing, Shanghai, Sichuan and Yunnan, the female old-care nursing members account for $83.5 \%$ of the total members; the nursing members who are 40 - 49 years old make up 51.0\%, 50 years old and above, 28.1\%; the nursing members whose education degree is primary school and below account for 21.7\%; middle school, 45.2\%; and agricultural registered permanent residences, accounting for 55.8\%. The nursing members whose entire period of actual operation is less than 1 year account for $14.8 \%$ of the total, and 1 - 2 years of working experience, $25.9 \%$; 3 - 5 years of working experience, $30.6 \%$. The nursing members in formal establishment account for $25.9 \%$ of the total, and nursing member beyond formal establishment, $74.1 \%$. The ones who signed labor contract make up $64.9 \%$ of the total, the ones failing to sign labor contract, $27.8 \%$. Nursing members who are well trained account for $73.5 \%$, the ones failing to be trained, 26.5\%; the ones without qualification certificate, 39.8\%; the ones possessing junior certificates, 41.9\%; intermediate certificates, $13.3 \%$; senior certificates, $4.1 \%$. Nursing members whose monthly income is between RMB 1000 - 1499 account for 42.9\% of the total, RMB 1500 - 1999, 34.8\%. Additionally, 27.6\% of nursing members feel unsatisfactory to their income. The nursing members who suffer from serious psychological pressure make up 21.9\%; moderate psychological pressure, 26.7\%. The nursing members who will change their careers account for 27.7\%; uncertain, 35.4\%. Other elderly support staff (including caseworkers, medical staff, health recovery staff and elderly-support volunteers) who is in formal establishment accounts for $36.1 \%$, $26.6 \%$ of the total staff intend to change their carriers. The data above verifies the fact that the cultivation of professional talents lags far behind the establishment of elderly-support organizations. Severe shortage of elderly-support professionals is attributed to the following reasons: mobility of elderly-support service teams, difficult recruitment, unreasonable age structure, small occupational development potential, incomplete training mechanism, absence of mid \& long-term plan, irregular employment system, weak sense of identity, low salary, high labor intensity, high risks, etc.

\subsection{Low Resource Utilization Rate}

Firstly, some government functional departments focus on their own interests and refuse to break the existing boundaries in carrying out the home-based care services, for example, the civil affairs departments, which can allocate financial fund, welfare lottery fund, etc., focus on living material guarantee for "three without" people and low-income elders, the labor department concentrate on reemployment of female workers at the age of 40s to 50s, and the health departments only concern elders' healthcare, therefore, the join forces are not developed for propelling the sustainable and health development of the home-based care services. Secondly, elderly care resources are usually decentralized at separate communities and organizations, which only serve their own elders 
without sharing with others. And thirdly, due to insufficient communications among the government, the society and the market, the shared mechanism between elderly care facility and service market resources is not actually established, and elderly care service requirements at all levels can not be fulfilled [4].

\section{Proposals on the Market-Oriented Operation of Home-Based Care Services}

\subsection{Advocating the Concept of Home-Based Care Services}

As an innovative mode, the mode of home-based care services is essentially different from traditional family supporting mode, which will not be deeply rooted among the people without actively publicity and advocacy [5]. The government, as the advocator of such mode, is obliged to publicize the trend of population aging in our country to the whole society, advocate the home-based care service system, encourage the consumption concept of "paying for services", deepen people's sense of approval for the home-based care services, gradually change the elders' traditional consumption concept and consumption behavior and lay the foundation of a large-scaled home-based care service market. On the other hand, such active advocacy may also attract social investment for elderly care services, which will provide more support and increase both demand and supply, and actually bring the home-based care services a sustainable and health development.

\subsection{Widening Development Space of Non-Governmental Capitals in House-Based Care Service Industry}

Successful running of market-oriented mechanism is inspired by economic benefits received by market activity participants. Elderly support industry has obvious external economic feature and is bound to lag behind demands only by relying on social forces. In addition, the balance point for the loss and profit for the elderly support industry, as the meager profit industry, is relatively high and its nature determines hard operation. Participation of social forces may be considered as "contribution" or sharing of the responsibilities carried by the government. For the elderly-support service industry, it is bound to shrink if no preferential policy is provided for compensation, thus adversely influencing the supply of care service to the elderly. Therefore, all-round supports shall be provided to facilitate participation of more non-governmental capitals into house-based care service. Firstly, positive measures shall be developed. Access system and program management system shall be established based on the principle of mutual benefit to encourage and support participation of various civil associations, enterprises and individuals into house-based care service by the manners of "purchasing service", "contracting-out" and "entrustment" [6]. Secondly, the possibility of establishing public financial investment mechanism shall be explored to raise social funds in several channels, thus providing more relax surviving and development space to the civil associations and providers which are engaged in house-based care service. Thirdly, incentive mechanism shall be established. Incentives and support shall be granted after comprehensive examination is made to the size, service items and social benefit of private house-based care service organizations, so as to provide more supports in development of house-based care service market.

\subsection{Improving Specialization Level of Management and Service Staff}

Efforts shall be made to develop a set of complete management and service staff cultivation and management system with respect to recruitment, training, salary and benefit, and management. Firstly, appropriate measures shall be taken to combine training of house-based care service workers and the laid-off workers re-employment programs. The laid-off workers who meet relevant requirements get together to learn professional care knowledge and go to duty until work permits are obtained. In this way, sound moral accomplishment and basic skills can be guaranteed at the beginning of professional team establishment process. Secondly, elderly-support service management specialty shall be set. Qualified colleges, universities and vocational education institutions shall be encourage and supported to set such specialties as elderly-support management and service, aged care, geriatric sociology and development of products for the aged. The competent administrative authorities shall grant preferential policies to the foregoing colleges and institutions with respect to enrollment, charge and infrastructure construction. Thirdly, nursing member periodic training system shall be maintained. Cooperation shall be developed together with colleges, universities and health professional schools, to offer systematic training to the nursing members serving existing elderly support organizations and communities, so as to assist the nursing members in grasping basic health, care, recovery knowledge and skills. Forth: elderly support professionals shall 
be introduced. While improving the quality of exiting nursing members, best efforts shall be done to introduce talents. Namely, young and excellent talents with high education degree shall be introduced to the house-based care service team through open recruitment, engagement and directed education. Meanwhile, the laid-off workers who possess some skills and business quality should be recruited to serve the institutional or community elderly support field [7].

\subsection{Increasing the Home-Based Care Service Staff's Remuneration}

Work nature, work meaning, work contents and work requirements of the home-based care service staff shall be strictly defined to differ from those of the ordinary household services. Publicization shall be carried out to improve the society's recognition and respect to the home-based care service staff. More government subsidies and basic insurances such as endowment insurance, medical insurance, work-related injury insurance, unemployment insurance, etc. shall be ensured and paid in full for the home-based care service staff based on labor guarantee policies. The home-based care service staff shall be, on basis of social worker's occupation level evaluation system, given corresponding material treatment. As for qualified home-based case service staff, they shall be entitled to related employment and reemployment supporting policies.

\section{Conclusion}

With the acceleration of the aging process in Sichuan, the demand for home care service for elderly people is urgent, but the current home care service supply seriously lags. Home care service market is a prominent problem such as the government dislocation, the operation of the market mechanism being not perfect, the lack of talents, the low efficiency of resource utilization. There is urgent need to take measures to promote the concept of home care services, broaden the development of private capital in the home care service industry, improve the management and service staff of professional level, and improve the treatment of home care service personnel.

\section{Acknowledgements}

This paper is funded by Sichuan philosophical and social science program (program code: 13S004, Research of Market-oriented Operation of House-based Care Service Market in Sichuan against the Background of Newtype Urbanization) and general scientific and research initialization program of Sichuan Normal University (Research of Procurement by the Government to Social Forces—-taking Jinjiang District, Chengdu City for instance). I am very grateful to the two funds for the support of this article.

\section{References}

[1] Office of the State Council (2011) Notice of the General Office of the State Council on Issuing the Social Pension Service System Construction Plan (2011-2015). http://www.gov.cn/zwgk/2011-12/27/content_2030503.htm

[2] Sun, H.F. (2010) Research on the Responsibility of the Government in the Home Care Service System in China. Lanzhou Journal, 4, 86-89.

[3] Liu, H.Q. and Bao, G.X. (2012) Study on Purchasing Management Mechanism of Home-Based Care Services to the Government-Taking the Chengguan District of Lanzhou City "Virtual Nursing Home” as an Example. Theory and Reform, 1, 67-70.

[4] Jing, Y.J. and Chen, R.J. (2009) The Development and Management Innovation of Home Care System in China: A Perspective of Coordination. Fudan Journal (Social Sciences), 5, 133-140.

[5] Xu, X.W. and Zhang, X.K. (2013) An Analysis on the Issue of Home-Based Care Services in Chinese City Communities. Journal of Shandong University of Finance, 1, 78-85.

[6] Mu, G.Z. (2012) Public Pension Institutions “Chaos” Governance. People’s Tribune, 11, 54-55.

[7] Xiu, H.F. (2013) Research on Community Service Support Home Care Service—Case Study on Harbin Heilongjiang Province. Doctoral Dissertation, Nankai University, Tianjin. 